\title{
Long-term Outcomes of Drug-eluting Stents in Symptomatic Intracranial Stenosis
}

\author{
Soonchan Park, MD, Dong-geun Lee, MD, Won-Jung Chung, MD, \\ Deok Hee Lee, MD, Dae Chul Suh, MD
}

Purpose: The use of drug-eluting stent (DES) to treat intracranial stenosis has shown short-term success. However, there are no reports regarding the long-term results of DES. We present the long-term clinical outcome after DES stenting for symptomatic severe intracranial stenosis.

Materials and Methods: Our study included a consecutive series of 11 patients who underwent intracranial stenting using DES between March and July, 2006, during the time when bare metal stents were not available at our medical institution. The mean patient age was 59 years. Lesion location was the middle cerebral artery in five patients, the intradural vertebral artery in three, the basilar artery in one, the vertebrobasilar junction in one, and the cavernous internal cerebral artery in one patient. We evaluated the technical success, defined as reduction of residual stenosis $\leq 30 \%$ in the target lesion) as well as the clinical and imaging outcomes as long as 75 months following the procedure. In addition to a cerebral angiogram $(n=2)$, follow-up study was obtained by CT angiography $(n=6)$ or intracranial Doppler imaging $(n=2)$ during a mean time of 55 months after the procedure (range, 24 to 73 months). Three patients refused imaging follow-up and accepted only clinical follow-up. The mean clinical follow-up period was 67 months (range, 47-75 months).

Results: Stenting in all patients was technically successful and without periprocedural complications. There was thrombus formation during the procedure in one patient who experienced no further complications. There were no new neurological events during the mean follow-up period of 5.6 years. No patients were found to have restenosis $\geq 50 \%$ at during the mean follow-up period of 55 months. One patient died of a sudden heart attack 59 months following the procedure which was regarded as unrelated to the cerebral lesion.

Conclusion: Our study demonstrates that DES shows long-term stability and safety, and results in good clinical outcomes with a low rate of restenosis.

Key Words : Drug-eluting stents; Intracranial stenosis; Atherosclerosis

All authors: Departments of Radiology and Research Institute of Radiology, University of Ulsan, College of Medicine, Asan Medical Center, Seoul, Korea

Received August 22, 2012; accepted after revision November 21, 2012.

Correspondence to: Dae Chul Suh, MD, Department of Radiology, University of Ulsan, College of Medicine, Asan Medical Center, 88, Olympic-ro 43-gil, Songpa-gu, Seoul 138-736, Korea.

Tel. 82.2.3010.4366 Fax. 82.2.476.0090 E-mail: dcsuh@amc.seoul.kr

This is an Open Access article distributed under the terms of the Creative Commons Attribution Non-Commercial License (http://creativecommons.org/licenses/by-nc/3.0) which permits unrestricted non-commercial use, distribution, and reproduction in any medium, provided the original work is properly cited. 
Despite the best medical therapy, the recurrent stroke rate due to ipsilateral intracranial stenosis is $11 \%$ during the first year, although it becomes nearly twice as high if the stenosis is $\geq 70 \%$ [1]. For those who fail their medical treatment, the recurrence rate may be as high as $52 \%$ [2]. Although bare metal stent (BMS) can be used for treating symptomatic intracranial stenosis $[3,4]$, the major concern is the rate of restenosis which is reported to be as high as $32 \%$ [5].

There have been several reports regarding both shortterm and mid-term follow-up results for the use of a drug-eluting stent (DES) for treating symptomatic intracranial stenosis [6-9]. However, the benefits of using DES have not been clearly defined in the cerebral arteries. There are also no reports regarding the longterm clinical and radiological outcomes following DES introduction. In this study, we present and discuss the long-term outcome in patients who underwent intracranial stenting with DES.

\section{MATERIALS AND METHODS}

\section{Patients}

This study is part of a prospective study which was approved by our institutional review board. Among the patients in the database, we selected patients who underwent intracranial DES between March 2006 and
July 2006. Presenting symptoms referring to the stenotic segment were transient ischemic attack (TIA) in nine and stroke in two. Revascularization was performed in patients with these symptoms as well as the medical therapy which includes an antiplatelet agent or warfarin as well as a lipid lowering agent.

The selection criteria for the endovascular treatment are as follows: 1) ischemic events caused by the stenotic artery; 2) continuing or aggravated ischemic symptoms despite medical therapy as defined by the regular use of at least $100 \mathrm{mg}$ aspirin or $75 \mathrm{mg}$ clopidogrel or anticoagulation by intravenous heparin (with an activated partial thromboplastin time $>1.5$ times control); and 3) stenosis degree $>50 \%$ seen on digital subtraction angiography.

All of our study patients were male, and the mean patient age was 59 years (35 78). The patient data and the procedures performed were summarized in Table 1 . The lesion locations where the stent was placed are as follows: middle cerebral artery $(n=5)$; the vertebral artery $(\mathrm{n}=3)$; the basilar artery $(\mathrm{n}=1)$; the vertebrobasilar junction $(n=1)$; and the cavernous internal carotid artery $(n=1)$. Initial presentation symptoms were TIAs $(\mathrm{n}=9)$ without showing an acute brain parenchymal lesion and stroke $(n=2)$ in patients whose brain MRI showed acute infarcts in the lateral medulla (patient 7) or pons (patient 10). The associated

Table 1. Summary of the Patients and Results

\begin{tabular}{|c|c|c|c|c|c|c|c|c|c|c|}
\hline $\begin{array}{l}\text { Patient } \\
\text { No. }\end{array}$ & $\begin{array}{l}\text { Age/ } \\
\text { Sex }\end{array}$ & $\begin{array}{l}\text { Presenting } \\
\text { symptom }\end{array}$ & $\begin{array}{l}\text { Lesion } \\
\text { location }\end{array}$ & $\begin{array}{l}\text { Stent diameter/ } \\
\text { Length }\end{array}$ & Image FU & $\begin{array}{l}\text { Last } \\
\text { FU }\end{array}$ & $\begin{array}{l}\text { Clinical } \\
\text { FU }\end{array}$ & Restenosis & $\begin{array}{c}\text { Events } \\
\text { during FU }\end{array}$ & $\begin{array}{l}\text { Final } \\
\mathrm{mRS}\end{array}$ \\
\hline 1 & $35 / M$ & TIA & M1 & $2.5 / 13$ & Angio at $13,25 \mathrm{~m}$ & TCD & $73 \mathrm{~m}$ & Yes $\rightarrow$ No & None & 0 \\
\hline 2 & $51 / \mathrm{M}$ & TIA & M1 & $3.5 / 13$ & Yearly TCD FU & TCD & $73 \mathrm{~m}$ & No & None & 0 \\
\hline 3 & $53 / \mathrm{M}$ & TIA & V4 & $3.0 / 13$ & Angio at $14 \mathrm{~m}$ & CTA & $60 \mathrm{~m}$ & No & None & 0 \\
\hline 4 & $56 / M$ & TIA & M1 & $3.5 / 13$ & CTA at $8,59,70 \mathrm{~m}$ & MRAP & $74 \mathrm{~m}$ & No & None & 0 \\
\hline 5 & $74 / \mathrm{M}$ & TIA & M1 & $2.5 / 13$ & CTA at $24,73 \mathrm{~m}$ & CTA & $73 \mathrm{~m}$ & No & None & 0 \\
\hline 6 & $40 / \mathrm{M}$ & TIA & BA & $3.5 / 13$ & CTA at $3,44 \mathrm{~m}$ & CTA & $73 \mathrm{~m}$ & No & None & 0 \\
\hline 7 & $78 / \mathrm{M}$ & Stroke & V4 & $3.0 / 13$ & Refuse & None & $73 \mathrm{~m}$ & No & None & 1 \\
\hline 8 & $69 / M$ & TIA & VBJ & $3.0 / 8$ & CTA at $16,58 \mathrm{~m}$ & CTA & $62 \mathrm{~m}$ & No & None & 0 \\
\hline 9 & $51 / \mathrm{M}$ & TIA & M1 & $2.5 / 13$ & CTA at $8,33,47 \mathrm{~m}$ & CTA & $47 \mathrm{~m}$ & No & None & 0 \\
\hline 10 & $68 / \mathrm{M}$ & Stroke & V4 & $3.0 / 13$ & Refuse & None & $59 \mathrm{~m}$ & NA & Death at $59 \mathrm{~m}^{*}$ & 6 \\
\hline 11 & $69 / M$ & TIA & Cav ICA & $3.5 / 13$ & Refuse & None & $75 \mathrm{~m}$ & NA & None & 0 \\
\hline
\end{tabular}

Abbreviations: TIA, transient ischemic attack; V4, the intradural vertebral artery segment; Cav ICA, the cavernous internal carotid artery; FU, follow-up; Angio, cerebral catheter angiogram; TCD, transcranial Doppler ultrasound; CTA, computed tomographic angiography; CTAP, CTA with perfusion; MRA, magnetic resonance imaging; MRAP, MRA with perfusion; NA, not available; mRS, modified Rankin Score

* : sudden cardiac death without any neurologic deficit during the follow-up period 


\section{Drug-eluting Stents for Intracranial Stenosis}

risk factors were hypertension $(\mathrm{n}=6)$, diabetes mellitus $(\mathrm{n}=1)$, hyperlipidemia $(\mathrm{n}=1)$, previous stroke $(\mathrm{n}=2)$, coronary artery disease $(\mathrm{n}=1)$, cigarette smoking $(\mathrm{n}=$ $7)$, and a family history of stroke $(n=2)$.

\section{Procedures}

The procedural details are the same as those described in previous reports [4, 10-13]. A Cypher (Cordis Corp, Johnson \& Johnson, Warren, NJ, USA) stent was delivered over a 0.014 -inch microwire in order to cover the lesion. The stent diameter was determined by not oversizing the non-diseased lumen diameter. The lesion length ranged from 0.84 to 1.90 $\mathrm{mm}$. After stenting and angioplasty, we performed a control angiogram in order to measure the diameter of the stented segment. Heparin was not reversed after the procedure, and all patients were admitted to the intensive care unit for $1-2$ days so we would be able to check for any postprocedural neurological changes or complications.

Technical success was defined as a reduction in stenosis to $\leq 30 \%$ luminal narrowing without abnormal dissection or distal embolization. We evaluated any periprocedural complications after stenting, such as TIA, minor stroke (modified Rankin Score $(\mathrm{mRS}) \leq 2$ ), major stroke $(\mathrm{mRS}>2)$ or hemorrhage.

\section{Clinical Follow-up}

The occurrence of a recurrent stroke or of a patient's death was reviewed by a chart review or telephone interview with the patient or the patient's relatives (if the patient was deceased) by one of the investigators. Review of the medical records was focused on any recurrent symptoms, functional status measurement by $\mathrm{mRS}$, and mortality. Clinical follow-up was available for these 11 patients. If a patient was not followed in an outpatient clinic, an experienced nurse telephoned the patients to evaluate the possibility of any clinically relevant event.

\section{Imaging Follow-up}

In eight patients, imaging follow-up was performed with cerebral angiography, CT angiography (CTA), and/or transcranial Doppler (TCD) at 30 days, six months, one year, and yearly thereafter. Follow-up study included CTA $(n=6)$ or TCD $(n=2)$ for eight patients and with a mean follow-up period of 55 months. Cerebral angiography was performed in two patients at 13 and 25 months in one patient and at 14 months in the other.

We evaluated the rate of restenosis which was defined as a luminal narrowing of $\geq 50 \%$ in the stented segment. Restenosis evaluation using CTA was determined by binary estimation $(>50 \%)$ after
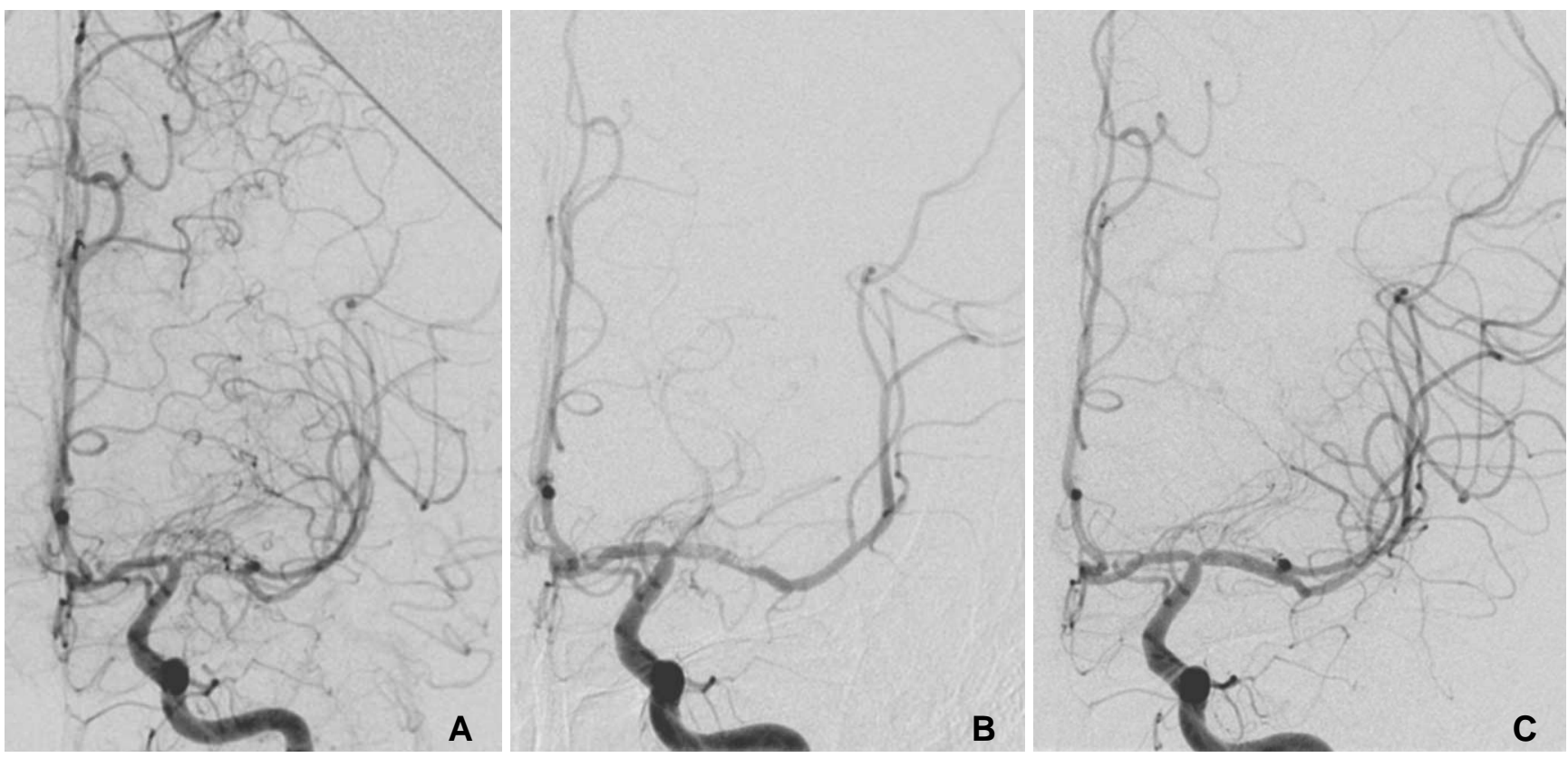

Fig. 1. A 35-year-old male presented with repeated TIAs against medication for 18 months. (A) The initial angiogram showed severe segmental stenosis of the left M1 and moyamoya-like collaterals around the stenosis. (B) There was an intraluminal filling defect after angioplasty and stenting, probably caused by incomplete antiplatelet medication or antiplatelet resistance. (C) The final angiogram obtained after intravenous antiplatelet agent infusion showed good patency of the M1. Also note the immediate disappearance of the moyamoya-like collaterals after stenting.

Continued 

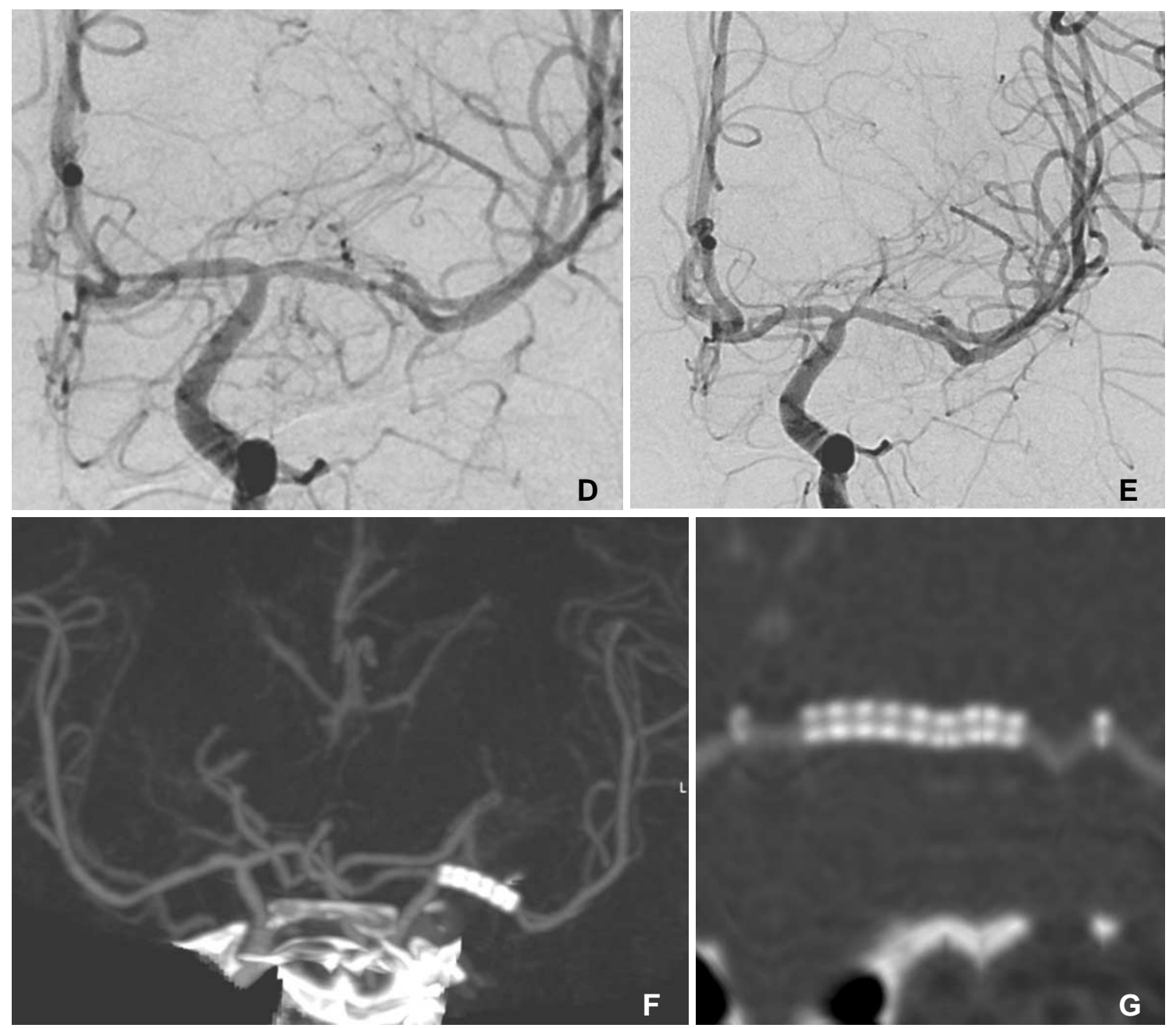

Fig. 1. (D) There was approximately $50 \%$ restenosis at the distal in-stent portion of the left M1, as seen on the 13-month follow-up angiogram, although the patient was without any symptoms. Cilostazol was added-added to the medication. (E) The restenosis had disappeared on the angiogram obtained 25 months later. $(\mathbf{F})$ There was no symptom recurrence or new symptoms and no evidence of restenosis on the CT angiography obtained 41 months later. Note the symmetric filling of both MCA branches. (G) The linearly reconstructed stent lumen shows luminal patency. Transcranial Doppler examination at 73 months showed slightly increased but similar peak systolic velocities in both M1s.

delineation of stented vessel segments by Advanced Vessel Analysis (Siemens, Erlangen, Germany) or visual inspection of the luminal patency along the stented vessel in conjunction with CT perfusion or on Doppler study below or above the stented vessels or on the contralateral side.

\section{RESULTS}

Both stent delivery and deployment were successful in all patients. The mean stenosis before treatment was $67 \%$, while the residual stenosis was less than $30 \%$ in all patients (mean $4 \%$ ). In patient 1 , there was intraluminal thrombus formation during the procedure and which responded to intravenous antiplatelet infusion without any further complications (Fig. 1). This thrombogenic event seemed to be related to incomplete antiplatelet medication or antiplatelet resistance which was not tested by VerifyNow system (Accumetrics, SanDiego, CA, USA) at that time. The follow-up results are included in Table 1.

Although image follow-up including TCD was done in eight of the 11 patient, there was no evidence of restenosis in any of these patients. The mean clinical follow-up period was 67 months (range, 47-75). Follow-up imaging was performed in $8 / 11$ patients $(73 \%)$ with CTA $(n=6)$, TCD $(n=2)$ or digital subtraction angiography (DSA) $(n=2)$. During the mean 55 months of imaging follow-up, suspected restenosis and then relief of the stenosis was seen during subsequent follow-up in two patients. Patient 1 had DSA follow-up at 13 months and 25 months 


\section{Drug-eluting Stents for Intracranial Stenosis}

although final follow-up was done by TCD. Patient 3 had DSA follow-up at 14 months although final follow-up was done by CTA.

In patient 1 , angiographic follow-up showed $50 \%$ instent restenosis at 13 months. Cilostazol $50 \mathrm{mg}$ bid was added to the patient's current medications of aspirin $100 \mathrm{mg}$ and clopidogrel $75 \mathrm{mg}$, after which the restenosis had disappeared on the 25-month follow-up angiogram. This patient showed almost a symmetric peak systolic velocity (PSV) in TCD (122 in the right M1 vs. 141 in left the M1) at 73 months.

Patient 2 with left M1 stenting revealed increased PSV (right M1 vs. the left M1 as 105 vs. 141), as seen on the 11-month follow-up, thus suggesting in-stent restenosis. However, subsequent follow-up revealed almost symmetric PSV on both sides, i.e. right vs. left as 89 vs. 69 at 24 months, 70 vs. 90 at 64 months, and 89 vs. 110 at 73 months, and which was interpreted as being within a normal range.

One patient died of a sudden heart attack 59 months following the procedure which was regarded as unrelated to the cerebral lesion.

\section{DISCUSSION}

Our previous study revealed that intracranial stenting using a bare metal stent can lead to a successful outcome $(\mathrm{mRS} \leq 2)$ in $97 \%$ of stable patients and in $67 \%$ of unstable patients [11]. The overall adverse event rate after intracranial stent placement within the 30 -day postprocedural period was $10 \%$ (9\% ipsilateral adverse event rate) $[11,14]$. Although there was no restenosis in our previous study, approximately $10-$ $20 \%$ restenosis is expected when using a bare metal stent and the amount is even higher, i.e. up to $30 \%$, when using Wingspan [15]. Stenting with DES in the intracranial vessel is recommended because of the high restenosis risk when using BMS [5]. Previous authors have shown successful results with DESs during the short and mid-term follow-up [6-9]. Our results also showed additional evidence of the good clinical outcome and no documented restenosis in our series even though our study included relatively a few patients during a mean 5.6 years, and thus indicating the long-term safety and durability of DES.

Although there are some reports regarding the likelihood of developing DES toxicity to the cerebral arteries in humans $[7,16]$, we did not experience any abnormal events during the procedure or the follow-up period due to the placement of DES. The use of DESs in coronary intervention has been shown to induce a low-grade chronic inflammatory process and impede the rate of endothelial healing [17]. These mechanisms have explained for the occurrence of very late reinfarction and stent thrombosis over the longer term even though they occur rarely [18].

Restenosis comes from a combination of the elastic recoil of the artery, neointimal hyperplasia, and vascular remodeling $[19,20]$. This process involves stimulation of smooth muscle cell migration, proliferation, and activation of endothelial cells at injury sites $[19,21]$. DESs are a major breakthrough in restenosis prevention after coronary intervention and they comprise more than $85 \%$ of the stents used in western countries $[22,23]$. Although delayed endothelialization [24] or delayed hypersensitivity to the stents and causing thrombosis [25] in the coronary vessels has been reported, there must be more clinical experience and careful observation regarding these complications. The low restenosis rate of our series might have been due to the low number of calcified lesions which significantly limit full expansion of the stents, thus leaving a higher chance for restenosis [26].

The stent length of the DESs used in our study was longer than the BMSs those we have been using at that time although DESs $8-9 \mathrm{~mm}$ long are now available in our country. Since the self-expanding Wingspan stent system became the only stent approved by the Food and Drug Administration for the treatment of intracranial atherosclerotic disease, the usage and debate regarding DES vs. BMS has subsequently decreased. Limitations of our study are that we included a limited number of patients and follow-up studies including CTA and TCD without the validation of DSA in all patients. However, evaluation of intracranial stenosis between CTA, TCD, DSA shows a moderate agreement [27]. And in case of no neurologic symptom aggravations, it is not always necessary and possible to perform DSA especially in long term follow-up study.

Despite these limitations, our study showed a favorable clinical outcome of DESs with a low rate of restenosis in selected patients over more than a 5.6-year follow-up period. DES can play a significant role in the management of intracranial stenosis and noninvasive image follow-up could be proper if clinical follow-up is combined.

\section{References}

1. Kasner SE, Chimowitz MI, Lynn MJ, Howlett-Smith H, Stern BJ, Hertzberg VS, et al. Predictors of ischemic stroke in the territory of a symptomatic intracranial arterial stenosis. Circulation 


\section{Soonchan Park, et al.}

2006;113:555-563

2. Thijs VN, Albers GW. Symptomatic intracranial atherosclerosis: outcome of patients who fail antithrombotic therapy. Neurology 2000;55:490-497

3. Suh DC, Ko YB, Park ST, Yoon K, Lim OK, Oh JS, et al. Computational flow dynamics of the severe $\mathrm{m} 1$ stenosis before and after stenting. Neurointervention 2011;6:13-16

4. Lu PH, Park JW, Park S, Kim JL, Lee DH, Kwon SU, et al. Intracranial stenting of subacute symptomatic atherosclerotic occlusion versus stenosis. Stroke 2011;42:3470-3476

5. SSYLVIA study investigators. Stenting of symptomatic atherosclerotic lesions in the vertebral or intracranial arteries (SSYLVIA): study results. Stroke 2004;35:1388-1392

6. Qureshi AI, Kirmani JF, Hussein HM, Harris-Lane P, Divani AA, Suri MF, et al. Early and intermediate-term outcomes with drugeluting stents in high-risk patients with symptomatic intracranial stenosis. Neurosurgery 2006;59:1044-1051

7. Abou-Chebl A, Bashir Q, Yadav JS. Drug-eluting stents for the treatment of intracranial atherosclerosis: initial experience and midterm angiographic follow-up. Stroke 2005;36:e165-168

8. Gupta R, Al-Ali F, Thomas AJ, Horowitz MB, Barrow T, Vora NA, et al. Safety, feasibility, and short-term follow-up of drugeluting stent placement in the intracranial and extracranial circulation. Stroke 2006;37:2562-2566

9. Steinfort B, Ng PP, Faulder K, Harrington T, Grinnell V, Sorby $\mathrm{W}$, et al. Midterm outcomes of paclitaxel-eluting stents for the treatment of intracranial posterior circulation stenoses. $J$ Neurosurg 2007;106:222-225

10. In HS, Lee HY, Park JY, Kim SY, Jung JH, Kim JS, et al. Intracranial stenting in patients with atherosclerotic stenosis associated with various aneurysms in the same diseased arterial segment. AJNR Am J Neuroradiol 2010;31:1895-1898

11. Suh DC, Kim JK, Choi JW, Choi BS, Pyun HW, Choi YJ, et al. Intracranial stenting of severe symptomatic intracranial stenosis: results of 100 consecutive patients. AJNR Am J Neuroradiol 2008;29:781-785

12. Pyun HW, Suh DC, Kim JK, Kim JS, Choi YJ, Kim MH, et al. Concomitant multiple revascularizations in supra-aortic arteries: short-term results in 50 patients. AJNR Am J Neuroradiol 2007;28:1895-1901

13. Suh DC, Kim SJ, Lee DH, Kim W, Choi CG, Lee JH, et al. Outcome of endovascular treatment in symptomatic intracranial vascular stenosis. Korean J Radiol 2005;6:1-7

14. Suh DC, Kim EH. The therapeutic time window related to the presenting symptom pattern, that is, stable versus unstable patients, can affect the adverse event rate of intracranial stenting. Stroke 2009;40:e588-589

15. Levy EI, Turk AS, Albuquerque FC, Niemann DB, Aagaard-
Kienitz B, Pride L, et al. Wingspan in-stent restenosis and thrombosis: incidence, clinical presentation, and management. Neurosurgery 2007;61:644-650

16. Boulos AS, Agner C, Deshaies EM. Preliminary evidence supporting the safety of drug-eluting stents in neurovascular disease. Neurol Res 2005;27(Suppl 1):S95-102

17. Farb A, Heller PF, Shroff S, Cheng L, Kolodgie FD, Carter AJ, et al. Pathological analysis of local delivery of paclitaxel via a polymer-coated stent. Circulation 2001;104:473-479

18. De Luca G, Dirksen MT, Spaulding C, Kelbaek H, Schalij M, Thuesen L, et al. Drug-eluting vs bare-metal stents in primary angioplasty: a pooled patient-level meta-analysis of randomized trials. Arch Intern Med 2012;172:611-621

19. Garas SM, Huber P, Scott NA. Overview of therapies for prevention of restenosis after coronary interventions. Pharmacol Ther 2001;92:165-178

20. Holmes DR, Jr., Vlietstra RE, Smith HC, Vetrovec GW, Kent KM, Cowley MJ, et al. Restenosis after percutaneous transluminal coronary angioplasty (PTCA): a report from the ptca registry of the national heart, lung, and blood institute. Am J Cardiol 1984;53: 77C-81C

21. Doggrell SA. Sirolimus- or paclitaxel-eluting stents to prevent coronary artery restenosis. Expert Opin Pharmacother 2004;5: 2209-2220

22. Klein LW. Are drug-eluting stents the preferred treatment for multivessel coronary artery disease? J Am Coll Cardiol 2006;47: $22-26$

23. Isenbarger DW, Resar JR. Drug-eluting versus third-generation bare metal stents: the us strategy. Int J Cardiovasc Intervent 2005; 7:171-175

24. Guagliumi G, Farb A, Musumeci G, Valsecchi O, Tespili M, Motta T, Virmani R. Images in cardiovascular medicine. Sirolimus-eluting stent implanted in human coronary artery for 16 months: pathological findings. Circulation 2003;107:1340-1341

25. Virmani R, Guagliumi G, Farb A, Musumeci G, Grieco N, Motta $\mathrm{T}$, et al. Localized hypersensitivity and late coronary thrombosis secondary to a sirolimus-eluting stent: should we be cautious? Circulation 2004;109:701-705

26. von Birgelen C, Mintz GS, Bose D, Baumgart D, Haude M, Wieneke $\mathrm{H}$, et al. Impact of moderate lesion calcium on mechanisms of coronary stenting as assessed with threedimensional intravascular ultrasound in vivo. Am J Cardiol 2003; 92:5-10

27. Roubec M, Kuliha M, Jonszta T, Prochazka V, Fadrna T, Filip M, et al. Detection of intracranial arterial stenosis using transcranial color-coded duplex sonography, computed tomographic angiography, and digital subtraction angiography. J Ultrasound Med 2011; 30:1069-1075 